\title{
Article \\ Gut Microbiota-Derived L-Histidine/Imidazole Propionate Axis Fights against the Radiation-Induced Cardiopulmonary Injury
}

\author{
Zhiyuan Chen ${ }^{1}$, Bin Wang ${ }^{1}$, Jiali Dong ${ }^{1}$, Yuan Li ${ }^{1}$, Shuqin Zhang ${ }^{1}$, Xiaozhou Zeng ${ }^{1}$, Huiwen Xiao ${ }^{2, *}$, \\ Saijun Fan ${ }^{1}$ and Ming Cui ${ }^{1, *}$ \\ 1 Tianjin Key Laboratory of Radiation Medicine and Molecular Nuclear Medicine, Institute of Radiation \\ Medicine, Chinese Academy of Medical Sciences and Peking Union Medical College, Tianjin 300192, China; \\ Chen_ZYuan@163.com (Z.C.); wangbinpumc@126.com (B.W.); dongjiali66@126.com (J.D.); \\ liyuan@irm-cams.ac.cn (Y.L.); zhangshuqin@irm-cams.ac.cn (S.Z.); zengxztj@student.pumc.edu.cn (X.Z.); \\ fansaijun@irm-cams.ac.cn (S.F.) \\ 2 Department of Microbiology, College of Life Sciences, Nankai University, Tianjin 300071, China \\ * Correspondence: xiaohw@nankai.edu.cn (H.X.); cuiming0403@bjmu.edu.cn (M.C.)
}

check for updates

Citation: Chen, Z.; Wang, B.; Dong, J.; Li, Y.; Zhang, S.; Zeng, X.; Xiao, H.; Fan, S.; Cui, M. Gut MicrobiotaDerived L-Histidine/Imidazole Propionate Axis Fights against the Radiation-Induced Cardiopulmonary Injury. Int. J. Mol. Sci. 2021, 22, 11436. https://doi.org/10.3390/ ijms222111436

Academic Editor: Orla L. Howe

Received: 17 September 2021

Accepted: 21 October 2021

Published: 23 October 2021

Publisher's Note: MDPI stays neutral with regard to jurisdictional claims in published maps and institutional affiliations.

Copyright: (c) 2021 by the authors. Licensee MDPI, Basel, Switzerland. This article is an open access article distributed under the terms and conditions of the Creative Commons Attribution (CC BY) license (https:// creativecommons.org/licenses/by/ $4.0 /)$.

\begin{abstract}
Radiation-induced cardiopulmonary injuries are the most common and intractable side effects that are entwined with radiotherapy for thorax cancers. However, the therapeutic options for such complications have yielded disappointing results in clinical applications. Here, we reported that gut microbiota-derived L-Histidine and its secondary metabolite imidazole propionate (ImP) fought against radiation-induced cardiopulmonary injury in an entiric flora-dependent manner in mouse models. Local chest irradiation decreased the level of L-Histidine in fecal pellets, which was increased following fecal microbiota transplantation. L-Histidine replenishment via an oral route retarded the pathological process of lung and heart tissues and improved lung respiratory and heart systolic function following radiation exposure. L-Histidine preserved the gut bacterial taxonomic proportions shifted by total chest irradiation but failed to perform radioprotection in gut microbiota-deleted mice. ImP, the downstream metabolite of L-Histidine, accumulated in peripheral blood and lung tissues following L-Histidine replenishment and protected against radiation-induced lung and heart toxicity. Orally gavaged ImP could not enter into the circulatory system in mice through an antibiotic cocktail treatment. Importantly, ImP inhibited pyroptosis to nudge lung cell proliferation after radiation challenge. Together, our findings pave a novel method of protection against cardiopulmonary complications intertwined with radiotherapy in pre-clinical settings and underpin the idea that gut microbiota-produced L-Histidine and ImP are promising radioprotective agents.
\end{abstract}

Keywords: radiation-induced cardiopulmonary injury; gut microbiota metabolites; imidazole propionate; pyroptosis; L-histidine

\section{Introduction}

Cancer ranks as the top public enemy and is the illness with the highest incidence and largest patient number in the world. Because of technological advancements, the number of cancer survivors is gradually reaching 33 million [1]. In developed countries, radical medical resources result in $67 \%$ of cancer patients surviving for more than 5 years, with about $25 \%$ of patients surviving for more than 15 years. However, cancer survivors often suffer from adverse side effects that are ineluctably intertwined with treatments such as radiotherapy, chemotherapy, or immunotherapy [2]. As a first-line therapeutic option for multiple kinds of cancer, about $50 \%$ of patients with solid tumors require radiotherapy for curative treatment [3]. Although advances in delivery technology have transformed the remedy into a more precise treatment, radiotherapy is still entwined with short-term side effects such as mucositis and long-term side effects such as tissue fibrosis $[4,5]$. Radiotherapy for thoracic tumors often burdens the lungs and heart and leads to complications, such as pneumonia, cardiac pericarditis, cardiomyopathy, and pulmonary 
and myocardial fibrosis, which can occur months to years after radiotherapy [6]. In light of these orchestrated intercorrelations, the lungs and heart are collectively considered as the cardiopulmonary system. For instance, local lung irradiation causes pathologic changes in the heart and vice versa [7]; however, the underlying mechanisms are diversiform and sophisticated [8,9]. Therefore, the loss of cardiopulmonary function is further aggravated when both the lungs and heart are exposed to irradiation [10,11].

The gut microbiome plays important roles in human health [12]. Recently, burgeoning experimental and epidemiological evidence has highlighted the substantive intercorrelations between intestinal flora and the lungs, which has been termed as the "gut-lung axis" [13]. Gut microbiota-derived components, such as short-chain fatty acids (SCFA), penetrate into the circulatory system and serve as key messengers to connect the gut and lungs $[10,14,15]$. The crosstalk between host and gut microorganisms as well as the interactions within the gut microorganisms themselves induce short- and long-term effects. The gut-lung axis can shape the immune response in lung tissues and can interfere with the process of respiratory diseases [16]. Gut dysbiosis not only precipitates digestive tract diseases such as inflammatory bowel disease but also renders chronic obstructive pulmonary disease and asthma14. In addition, mounting evidence has proven that the gut microbiome is involved in cardiovascular disease, and changes in gut microbiome have been reported to cause atherosclerosis [17]. In the "gut-heart axis", the metabolites produced by the gut microbiota also serve as essential linkers. For example, SCFAs are recognized as safeguards for cardiovascular diseases, while trimethylamine-N-oxide is considered to be an accessary to elicit cardiovascular diseases $[15,18]$.

In this study, we aimed to screen bioactive compounds from gut microbiota-derived metabolites to battle against radiation-induced cardiopneumatic injuries. Our observations demonstrated that the L-Histidine/ImP axis lulled the pathological processes of the lung and heart tissues and ameliorated lung respiratory and heart systolic functions following radiation stimuli in a gut microbiota-dependent fashion. Mechanistically, ImP blocked pyroptosis to propel the proliferation of pneumonocytes. Together, our findings provide novel insights into the function and the underlying protective mechanism of microbiota metabolites in the context of radiation-induced cardiopneumatic toxicity in preclinical settings.

\section{Results}

\subsection{Gut Microbiota-Derived L-Histidine Improves Radiation Toxicity in Lung and Heart}

In light of our previous study, total chest irradiation (TCI) decreased the level of L-Histidine in fecal pellets, which was reversed following fecal microbiota transplantation (FMT, Figure S1A). Given the remedial effects of the gut microbiome on radiation pneumonic toxicity, we treated the local chest-irradiated mice with L-Histidine via the oral route for 10 days, and the sham radiation and TCI-only group were given equal doses of placebo. As shown in Figure 1A, L-Histidine replenishment prevented weight loss, implying that L-Histidine might have had the potential to improve the radiotherapy prognosis for thorax cancers. Then, we assessed the levels of L-Histidine in feces, serum, and lung and observed that L-Histidine accumulated in the three parts following oral gavage (Figures $1 \mathrm{~B}$ and S1C,D). Next, Sirius Red and Masson staining revealed the structural damage and collagen accumulation of the alveoli in irradiated mice, while L-Histidine attenuated the pathological process (Figure 1C,D). L-Histidine also erased the elevation of the lung coefficient following TCI (Figure 1E), suggesting that L-Histidine might improve lung function after radiotherapy. Indeed, L-Histidine treatment increased the respiratory quotient $(\mathrm{RQ})$ value, decreased $\mathrm{VO}_{2}$ intake emissions, and alleviated pneumonia, as judged by the reduction of radiation-elevated pro-fibrotic and pro-inflammatory factors (Figures $1 \mathrm{~F}-\mathrm{H}$ and $\mathrm{S} 1 \mathrm{~B}, \mathrm{E}-\mathrm{H}$ ). In line with the above observations, L-Histidine also hindered the structural damage and collagen accumulation in heart tissues (Figure 1I,J), recovered systolic and diastolic pressure (Figures $1 \mathrm{~K}$ and $\mathrm{S1I}$ ), and lessened the inflammatory status of the heart tissues in mice 
with local chest irradiation (Figures $1 \mathrm{~L}$ and S1J-L). Together, our observations demonstrate that l-Histidine protects against radiation toxicity in both lung and heart tissues.
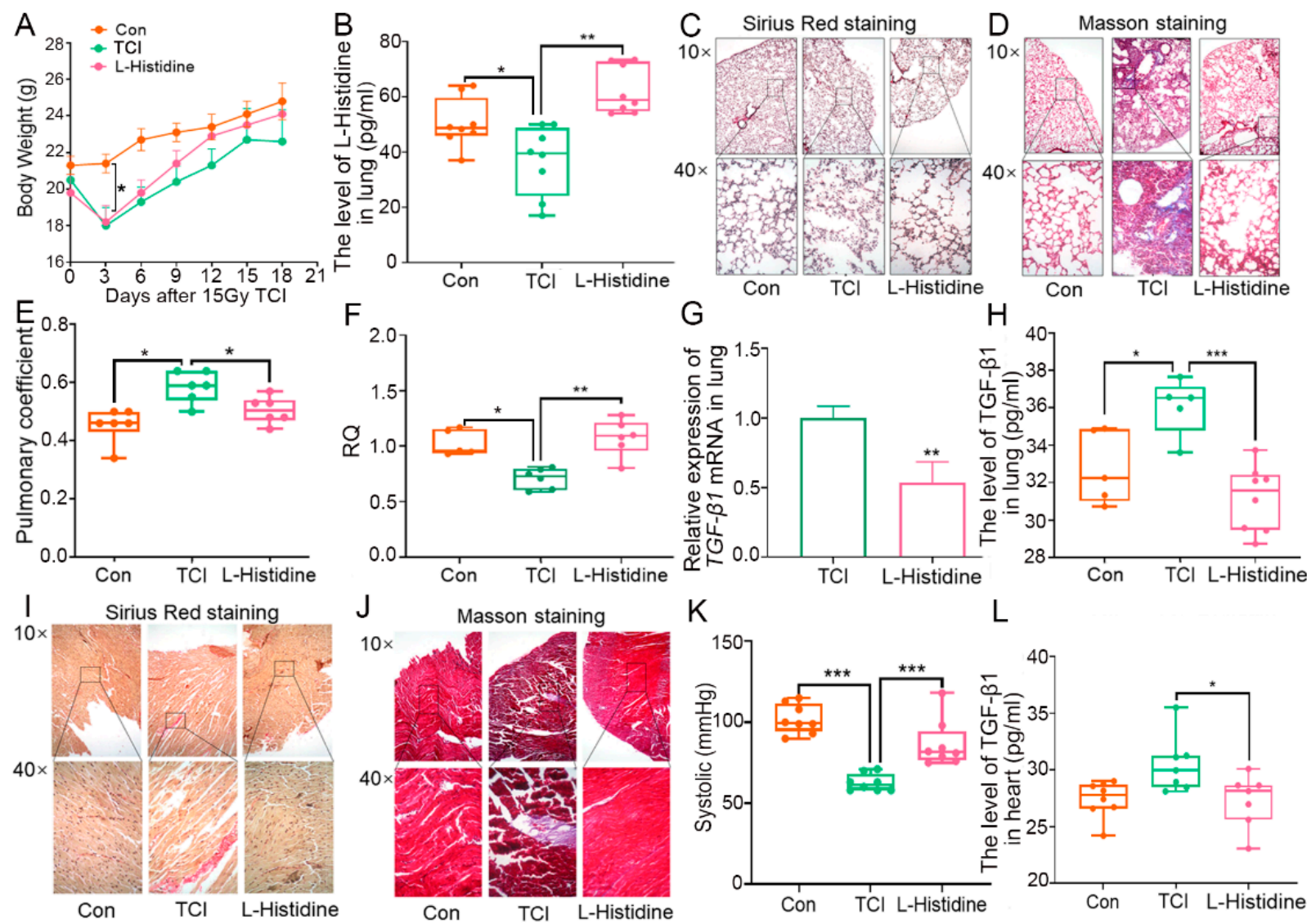

Figure 1. Gut microbiota-derived L-Histidine improves radiation toxicity in lungs and heart. (A) Body weight of mice after 15 Gy TCI and L-Histidine treated group after TCI. (B) The L-Histidine expression in lung tissues by ELISA $(n=8)$. $(\mathbf{C}, \mathbf{D})$ The lung tissues of each group mice were stained with Sirius Red (C) and Masson (D) and were observed under $10 \times$ and $40 \times$ microscopes, respectively. (E) Determination of the pulmonary coefficient in each group of mice $(n=6)$. (F) RQ of mice in each group of mice in $24 \mathrm{~h}(n=6)$. $(\mathrm{G}, \mathrm{H})$ The TGF- $\beta 1$ levels in lung tissues of each group mice were assessed by q-PCR and ELISA $(n=6)$. (I,J) The heart tissues of each group mice were stained with Sirius Red (I) and Masson (J) and were observed under $10 \times$ and $40 \times$ microscopes, respectively. (K) The systolic of each group of mice $(n=8)$. (L) The TGF- $\beta 1$ levels in the heart tissues of each group mice were assessed by ELISA $(n=7)$. (The data are presented as mean \pm SD, ${ }^{*} p<0.05,{ }^{* *} p<0.01$ and ${ }^{* * *} p<0.001$; Student's $t$-test).

\subsection{L-Histidine Shapes the Gut Microbiota Configuration after Chest Local Irradiation}

Owing to the enrichment of L-Histidine in the fecal pellets, 16S rRNA sequencing was performed to analyze whether L-Histidine impacted gut microbiota with radiation stimuli. Local chest irradiation heightened the $\alpha$-diversity of the intestinal bacteria, while L-Histidine erased the elevation (Figures 2A,B and S2A,B). Although both weighted and unweighted unifrac analyses showed no significant changes in the $\beta$-diversity (Figures 2D and S2C), and principal component analysis (PCA) and unweighted/weighted principal coordinate analysis (PCoA) validated the separations of the gut microbiota composition among the three cohorts (Figure 2C,E,F), indicating that L-Histidine indeed shifts the gut microbiota community in irradiated mice. In detail, the TCI-exposed mice showed a reduction in Akkermansia_muciniphila, Lactobacillus_reuteri, Clostridium_sp_Cuiture-41, lachnospiraceae_bacrerium_615, Ileibacterium_valens, and Helicobacter_bills at the species level, which were enriched following L-Histidine replenishment (Figure 2G). Together, all of the evidence seen here bolsters that L-Histidine treatment restructures the gut microbiota configuration in local chest-irradiated mice. 

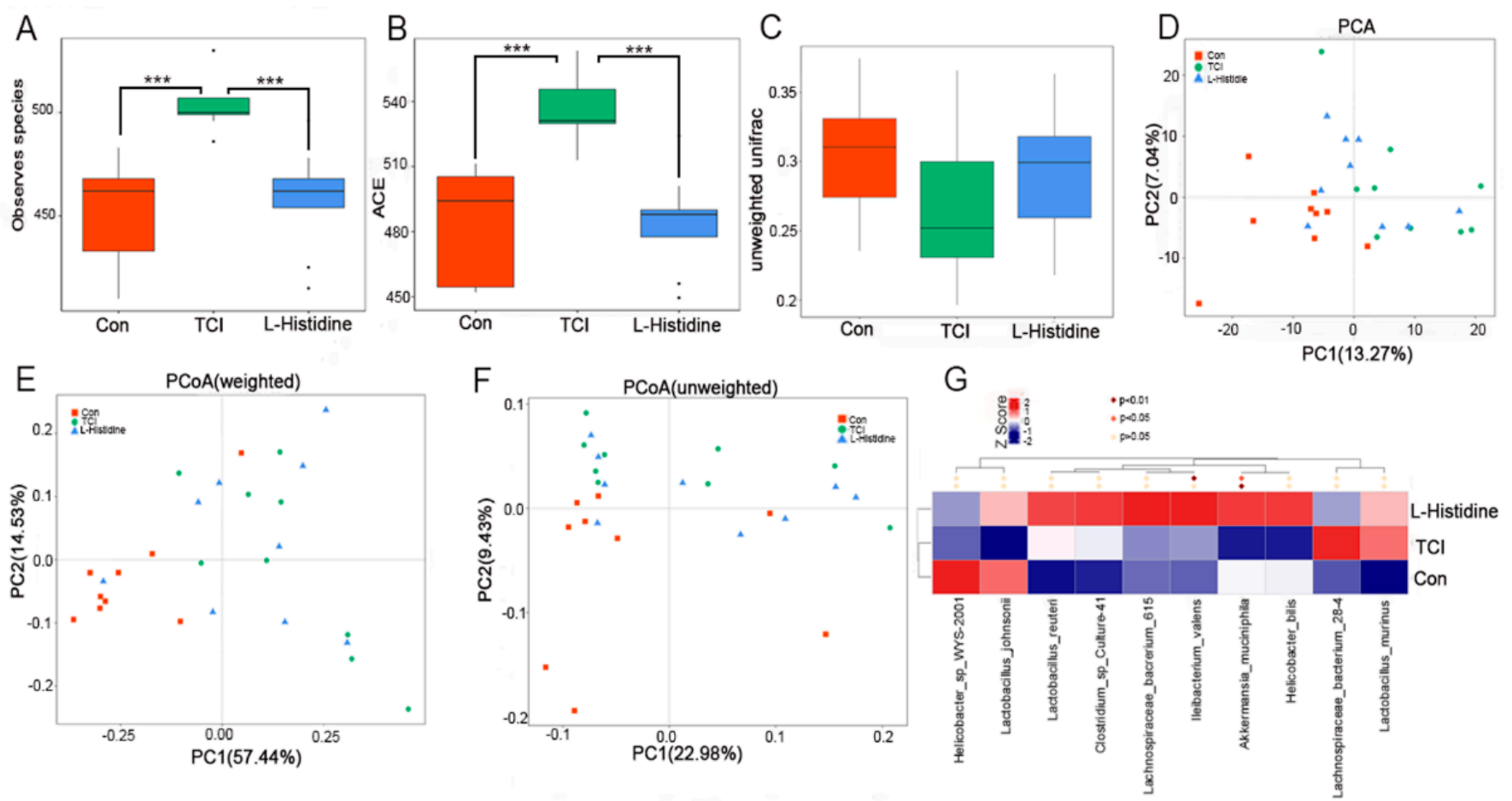

Figure 2. L-Histidine shapes the gut microbiota configuration after local chest irradiation. (A,B) The $\alpha$-diversity of gut bacteria was measured by $16 \mathrm{~S}$ rRNA high-throughput sequencing. In detail, the data were represented as the observed species number (A) and the ACE diversity index (B); (C,D) The $\beta$-diversity of enteric bacteria was compared by unweighted (C) and PCA (D) unifrac analysis. (E,F) PCoA were used to examine the alteration of the intestinal bacteria taxonomic pattern; (G) the heat map is color-based based on row Z-scores. The mice with the highest and lowest bacterial level are in red and blue, respectively. ( $n=8$ per group, the data are presented as mean $\pm \mathrm{SD},{ }^{* * *} p<0.001$, Statistically significant differences are indicated: Wilcoxon rank sum test).

\subsection{Gut Microbiota Contributes to L-Histidine-Mediated Radioprotection}

Next, we employed antibiotic-treated, gut microbiota-deleted mice to explore the role of intestinal flora in L-Histidine in terms of how it improved radiation pneumonic toxicity. In the first model, both groups were administrated L-Histidine, and an antibiotic cocktail (ABX) was added to the drinking water for one of the two groups. As shown by the Sirius Red and Masson staining, gut microbiota deletion interfered with L-Histidineprotected induced structural damage and collagen accumulation in local chest-irradiated mice (Figure 3A). In addition, ABX treatment also up-regulated the expression of profibrotic and pro-inflammatory cytokines in lung tissues (Figure 3B-D). In the second model $\mathrm{ABX}$ was added to the drinking water for the other two cohorts, and only one cohort was treated with L-Histidine. In parallel with the first model, L-Histidine replenishment failed to protect radiation-induced pneumonic injury when the gut microbiota was not present, as judged by the un-elevated body weight (Figure 3E) and RQ value (Figure 3F) as well as unchanged pro-fibrotic and pro-inflammatory factors (Figure 3G-I). All of the evidence manifests that L-Histidine protects against radiation-induced pneumonic injury depending on gut microbiota, at least partly. 

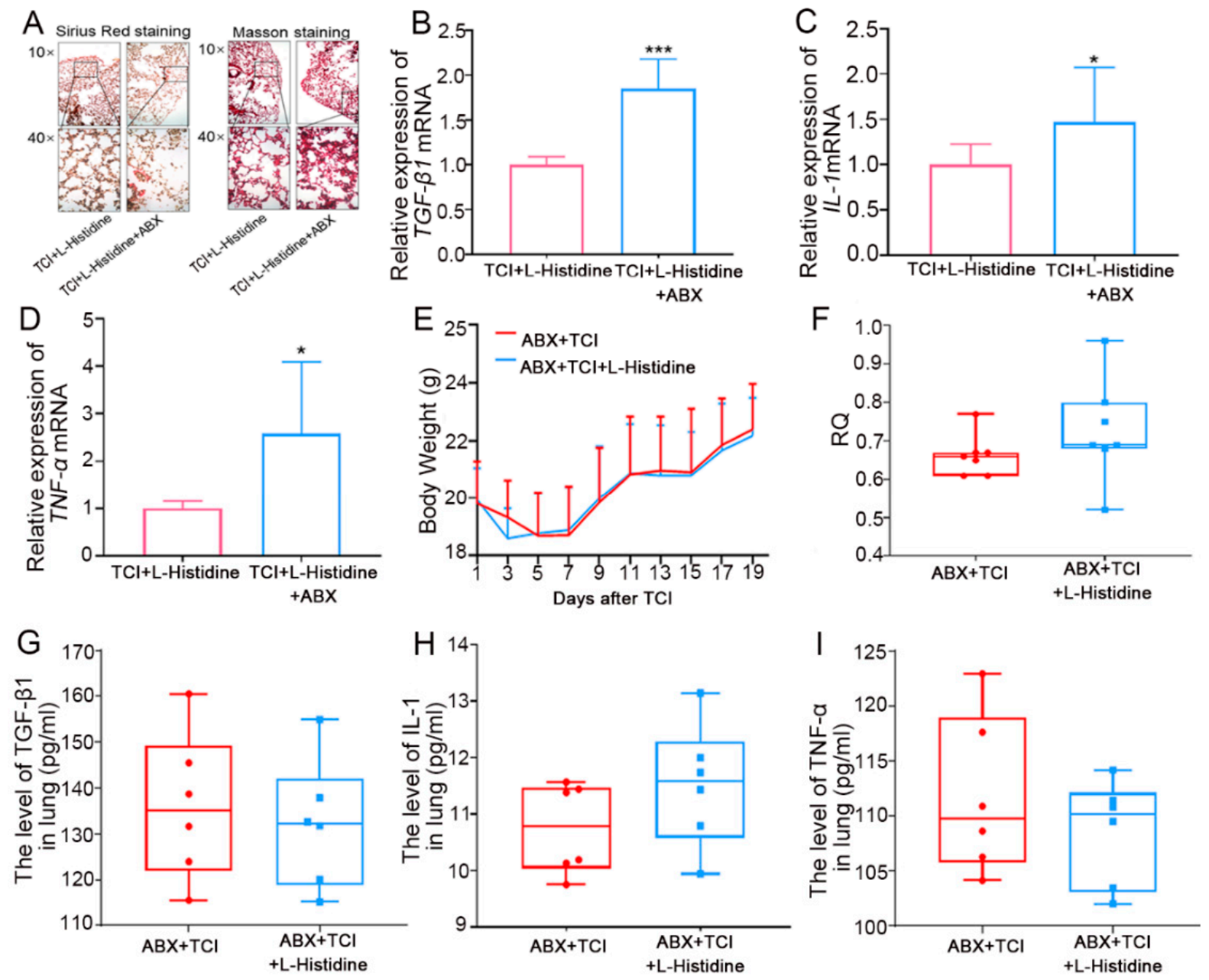

Figure 3. Gut microbiota contributes to L-Histidine-mediated radioprotection. (A) The lung tissues of each group mice were stained with Sirius Red and Masson in the ABX and L-Histidine and L-Histidine alone treated groups after TCI. (B-D) The TGF- $\beta 1$, IL-1 and TNF- $\alpha$ levels in lung tissues of each group of mice were assessed by q-PCR. (E) The body weight of each group of mice (not statistically significant). (F) The RQ in each group mice after $24 \mathrm{~h}(n=7)$. (G-I) The TGF- $\beta 1$, IL-1 and TNF- $\alpha$ levels in lung tissues of each group mice are assessed by ELISA $(n=6)$. (The data were presented as mean \pm SD, ${ }^{*} p<0.05$ and $^{* * *} p<0.001$; Student's $t$-test).

\subsection{L-Histidine Remolds the Gut Microbiota Metabolome Fluctuated by Local Chest Irradiation}

To further address the effects of L-Histidine on the gut microbiota after TCI, we assessed the metabolome of enteric flora using UHPLC-MS/MS. The heatmap described the details of metabolome changes. For example, TCI increased the relative abundance of 4-(acetylamino)phenyl 3-chlorobenzoate and abscisic acid but decreased that of 1-aspartic acid (Figure 4A). However, L-Histidine treatment elevated the frequency of prostaglandin f1 $\alpha$ and reduced that of testosterone sulfate (Figure 4B). All of the results further validated that TCI shaped the gut microbiota patten, which was restructured by L-Histidine replenishment. Given that L-Histidine is catabolized into ImP or histamine to favor physiological processes [19], we further assessed the levels of ImP and histamine in serum and lung tissues by ELISA. The results showed that only ImP and not histamine accumulated in serum and lung tissue following L-Histidine gavaging (Figure 4C-F), suggesting that ImP might be the key downstream metabolite of L-Histidine to protect the lungs and heart against irradiation. 

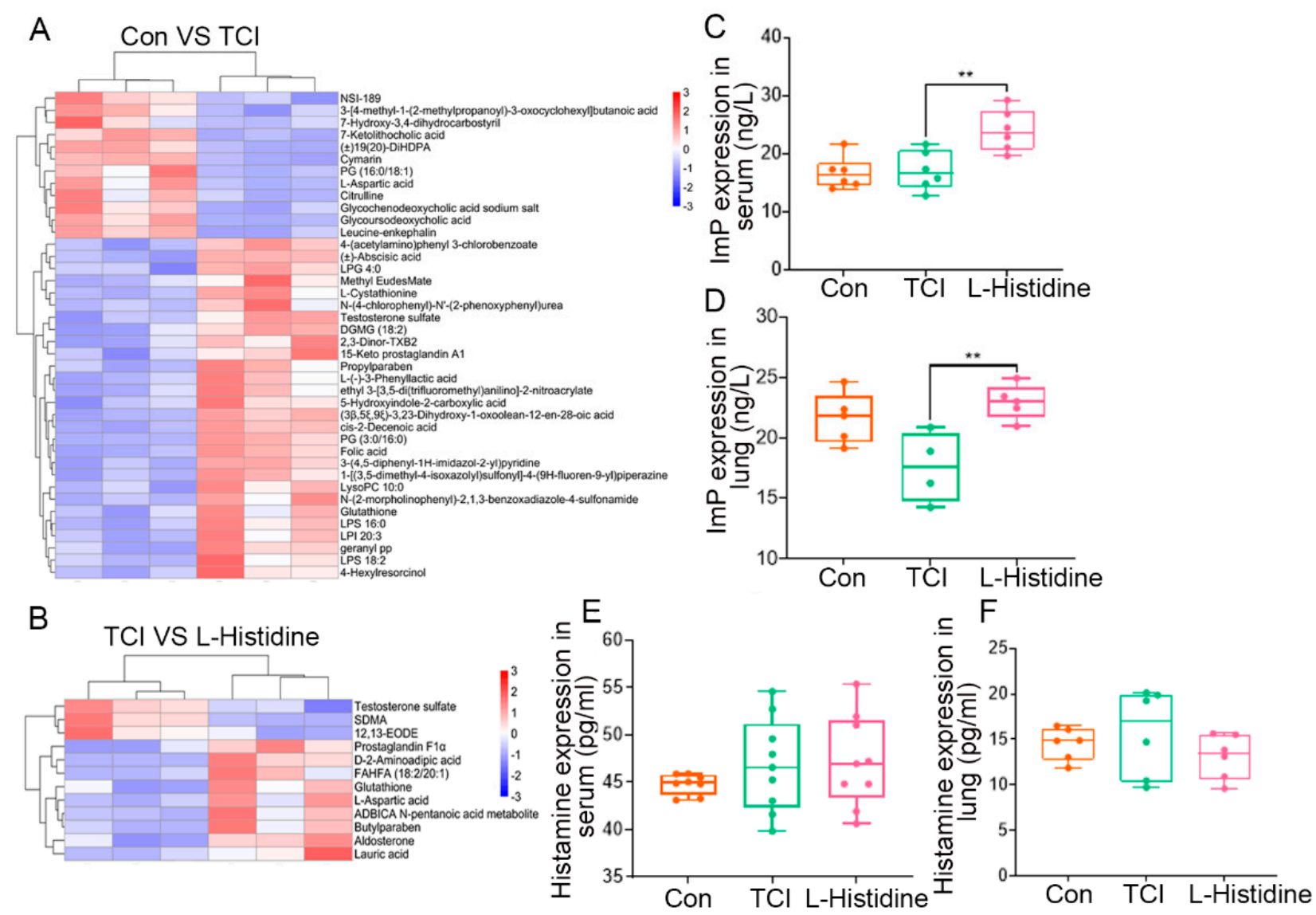

Figure 4. L-Histidine remolds the gut microbiota metabolome fluctuated by local chest irradiation. (A,B) Heatmap of the different identified metabolites in the fecal pellets from mice. In the volcano plots, each point represents a metabolite; (A) changes in the metabolites in the fecal pellets from mice in the TCI group and the control group; (B) changes in the metabolites in the fecal pellets from mice in the TCI group and L-Histidine group. (C,D) The ImP expression in serum $(n=6)$ and lung $(n=5)$ in each group. (E,F) The histamine expression in serum $(n=8)$ and lung $(n=6)$ in each group. (The data are presented as mean $\pm \mathrm{SD},{ }^{* *} p<0.01$; Student's $t$-test).

\subsection{Imidazole Propionate Ameliorates Chest Local Irradiation-Induced Toxicity}

Next, we treated local chest-irradiated mice with $\operatorname{ImP}$ for 10 days and obtained that $\mathrm{ImP}$ was accumulated in the lungs after oral gavaging (Figure $5 \mathrm{~B}$ ). Intriguingly, ImP administration impeded the weight loss of irradiated mice and prevented structural damage to the lung and collagen accumulation in alveoli (Figure 5A,C,D). Consistent with L-Histidine, ImP increased the RQ value and down-regulated the levels of pro-fibrotic and pro-inflammatory cytokines in the lung tissues and bronchoalveolar lavage fluid (BALF) following radiation challenge, indicating that $\mathrm{ImP}$, a secondary metabolite of L-Histidine, is able to fight against radiation-induced pneumonic injury (Figures $5 \mathrm{E}-\mathrm{H}$ and $\mathrm{S} 3 \mathrm{~A}-\mathrm{F}$ ). We also assessed radiation cardiac toxicity in this system. Sirius Red and Masson staining showed that ImP attenuated local chest radiation-induced structural damage and collagen accumulation in heart tissues (Figure 5I,J). In addition, oral gavaging of $\mathrm{ImP}$ restored systolic and diastolic pressure, reduced the heart inflammatory status of irradiated mice (Figures 5K,L and S3G-L). Together, our observations demonstrate that L-Histidine-derived $\mathrm{ImP}$ is a key element to protect against radiation-induced pneumonic and cardiac toxicity. 

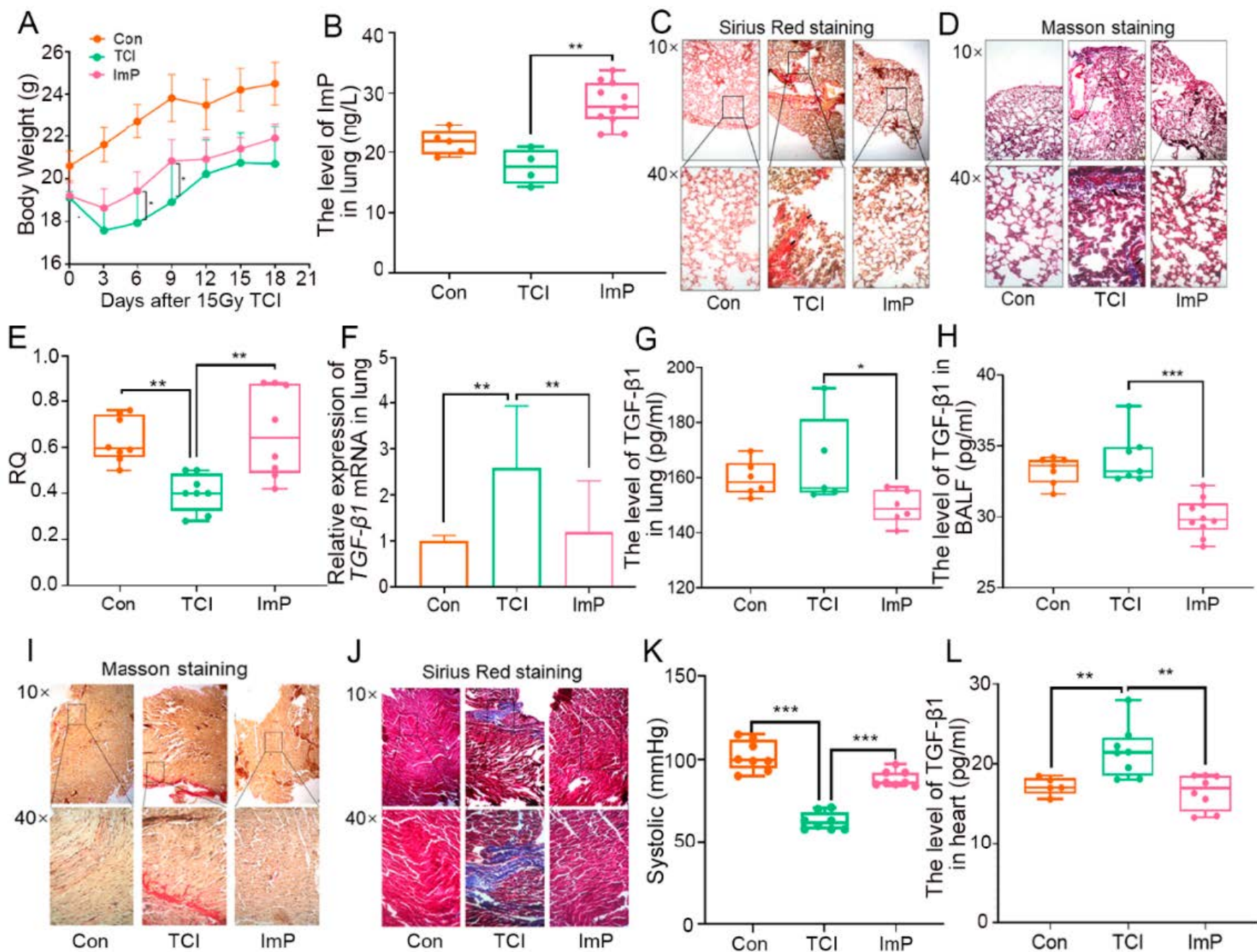

Figure 5. Imidazole propionate ameliorates chest local irradiation-induced toxicity. (A) Body weight of mice after $15 \mathrm{~Gy}$. (B) The ImP expression in lung tissues by ELISA $(n \geq 6)$. (C,D) The lung tissues of each group mice were stained with Sirius Red (C) and Masson (D) and were observed under $10 \times$ and $40 \times$ microscopes, respectively. (E) Respiratory quotient (RQ) of mice in each group mice in $24 \mathrm{~h}(n=8)$. $(\mathrm{F}, \mathrm{G})$ The TGF- $\beta 1$ levels in lung tissues of each group mice were assessed by q-PCR and ELISA $(n=6)$. (H) The TGF- $\beta 1$ levels in the BALF of each group of mice were assessed by ELISA $(n=8)$. (I,J) The heart tissues of each group of mice were stained with Sirius Red (I) and Masson (J) and were observed under $10 \times$ and $40 \times$ microscopes, respectively. (K) The systolic of each group of mice $(n=8)$. (L) The TGF- $\beta 1$ levels in heart tissues of each group mice were assessed by ELISA $(n=8)$. (The data are presented as mean $\pm \mathrm{SD},{ }^{*} p<0.05,{ }^{* *} p<0.01$ and ${ }^{* *} p<0.001$; Student's $t$-test).

\subsection{Gut Microbiota Impacts the Assimilation of Imidazole Propionate}

In light of the above results, L-Histidine might be catabolized into ImP or absorbed directly to perform radioprotective effects. Here, we used the aforementioned ABX treatment models to further assess whether $\mathrm{ImP}$ alleviates radiation toxicity relying on gut microbiota. In the first model, drinking water with $\mathrm{ABX}$ added to it interfered with the radioprotection of $\operatorname{ImP}$ to lung injury, as judged by lower $R Q$ value and higher pro-fibrotic and pro-inflammatory factors (Figures $6 \mathrm{~A}-\mathrm{E}$ and $\mathrm{S} 4 \mathrm{~A}, \mathrm{~B}$ ), inferring that the gut microbiota might bolster the radioprotective effects of ImP. In the second model, ABX-treated, gut microbiota-deleted mice did not respond to ImP implementation. In addition, ImP replenishment did not change the body weight (Figure 6F) or the RQ value (Figure 6G). Sirius Red and Masson staining revealed the similar structural damage and collagen accumulation in the alveoli caused by the irradiated mice between the two groups (Figure $6 \mathrm{H}$ ). The profibrotic and pro-inflammatory cytokines levels (Figures 6I,J and S4C) were also assessed in the gut microbiota-deleted mice. Finally, we assessed the ImP levels in the lung and 
serum in the mice who had undergone ABX treatment. Notably, the addition of $\operatorname{ImP}$ could not reach to peripheral blood and lung tissues without enteric bacteria (Figure $6 \mathrm{~K}, \mathrm{~L}$ ). We further used vancomycin or streptomycin to delete Gram-positive or Gram-negative bacteria, respectively, and observed that the accumulation of $\mathrm{ImP}$ in the lung tissue and serum was impaired in mice from the vancomycin treatment group (Figure S4D,E), suggesting that Gram-positive bacteria may play an important role in the absorption of imidazole propionate. All of these findings bolster that mice with an aberrant gut microbiome cannot absorb imidazole propionate into the blood and lung tissues from the digestive tract, suggesting that the gut commensal microbiota might contribute to the radioprotection of $\operatorname{ImP}$ for cardiopulmonary injury.
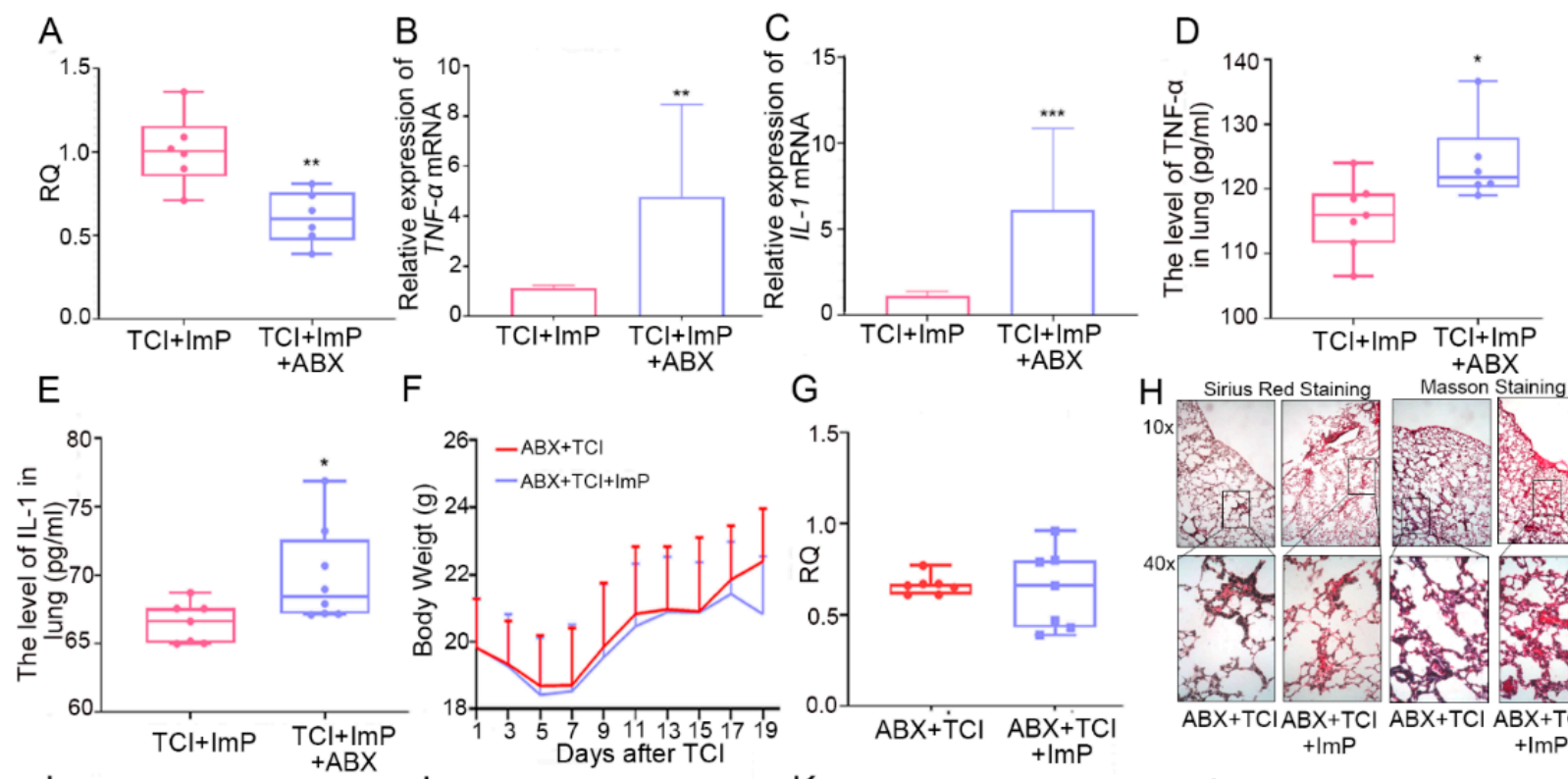

$\mathrm{F}$
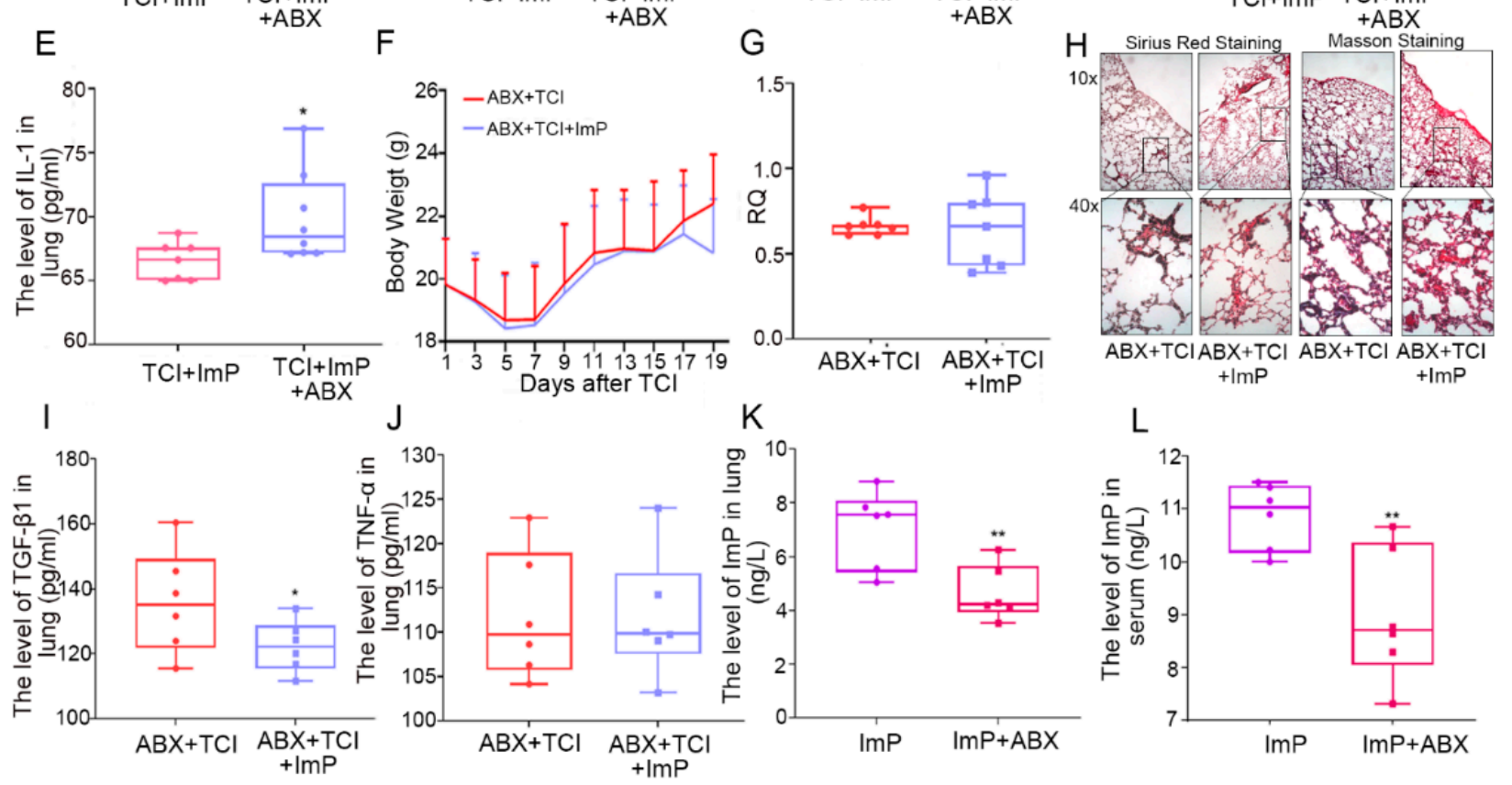

Figure 6. Gut microbiota impacts the assimilation of imidazole propionate. (A) The RQ in each group mice in $24 \mathrm{~h}(n=6)$. $(\mathbf{B}, \mathbf{C})$ The TNF- $\alpha$ and IL-1 levels in the lung tissues of each group mice were assessed by q-PCR. (D,E) The TNF- $\alpha$ and IL-1 levels in lung tissues of each group mice were assessed by ELISA $(n=6)$. (F) The body weight of each group mice (not statistically significant). (G) The RQ in each group of mice after $24 \mathrm{~h}(n=7)$. (H) The lung tissues of each group mice were stained with Sirius Red and Masson in the ABX-treated group after TCI. (I,J) The TGF- $\beta 1$ and TNF- $\alpha$ levels in lung tissues of each group of mice were assessed by ELISA $(n=6)$. (K) The level of ImP in lung were assessed by ELISA $(n=6)$. (L) The level of $\operatorname{ImP}$ in serum were assessed by ELISA $(n=6)$. (The data are presented as mean $\pm \mathrm{SD},{ }^{*} p<0.05,{ }^{* *} p<0.01$ and *** $p<0.001$; Student's $t$-test).

\subsection{Imidazole Propionate Inhibits Pyrolysis of Irradiated Lung Cells}

We further explored the underlying mechanism by which ImP protected radiationinduced lung toxicity. Clone formation assays showed that both L-Histidine and ImP facilitated the proliferation of human bronchial epithelial cells (BEAS-2B) in a dose-dependent manner after radiation exposure; however, ImP represented more obvious radioprotection (Figure 7A). In light of the results, $8 \mu \mathrm{L} / \mathrm{mL}$ of ImP was used as the optimal concentration 
in the subsequent experiments. Pyroptosis plays a key role in lung injury [20]. Thus, we assessed whether ImP could inhibit the pyrotosis of lung cells following irradiation. The IHC results showed that local chest irradiation elevated the level of Gasdermin D (GSDMD) in lung tissue, a classic marker of pyrotosis, which was erased by ImP replenishment (Figure 7B), and qRT-PCR assay revealed that ImP decreased irradiation-increased GSDMD, TNF- $\alpha$, and NF- $\mathrm{BB}$ expression in BEAS-2B cells, which was further validated by Western blotting, implying that Imp is able to lull radiation-precipitated pyroptosis in lung cells (Figure 7C-F). Pyroptosis is driven by caspase family activation and the cutting of GSDMD, resulting in the release of IL-1 $\beta$, IL-18, and other inflammatory factors. Accordingly, the addition of ImP inhibited the activation of caspase-1, caspase-4, and caspase- 5 in irradiated BEAS-2B cells (Figure 7G) and decreased IL-1 $\beta$ and IL-18 in the relative culture medium (Figure $7 \mathrm{H}, \mathrm{I}$ ). Immunofluorescence assay further showed that the addition of ImP elevated F-actin level to maintain the integrity of the cytoskeleton and to protect against mormorphic damage caused by pyroptosis (Figure 7J). Together, our observations demonstrate that ImP inhibits the pyroptosis of irradiated lung cells.
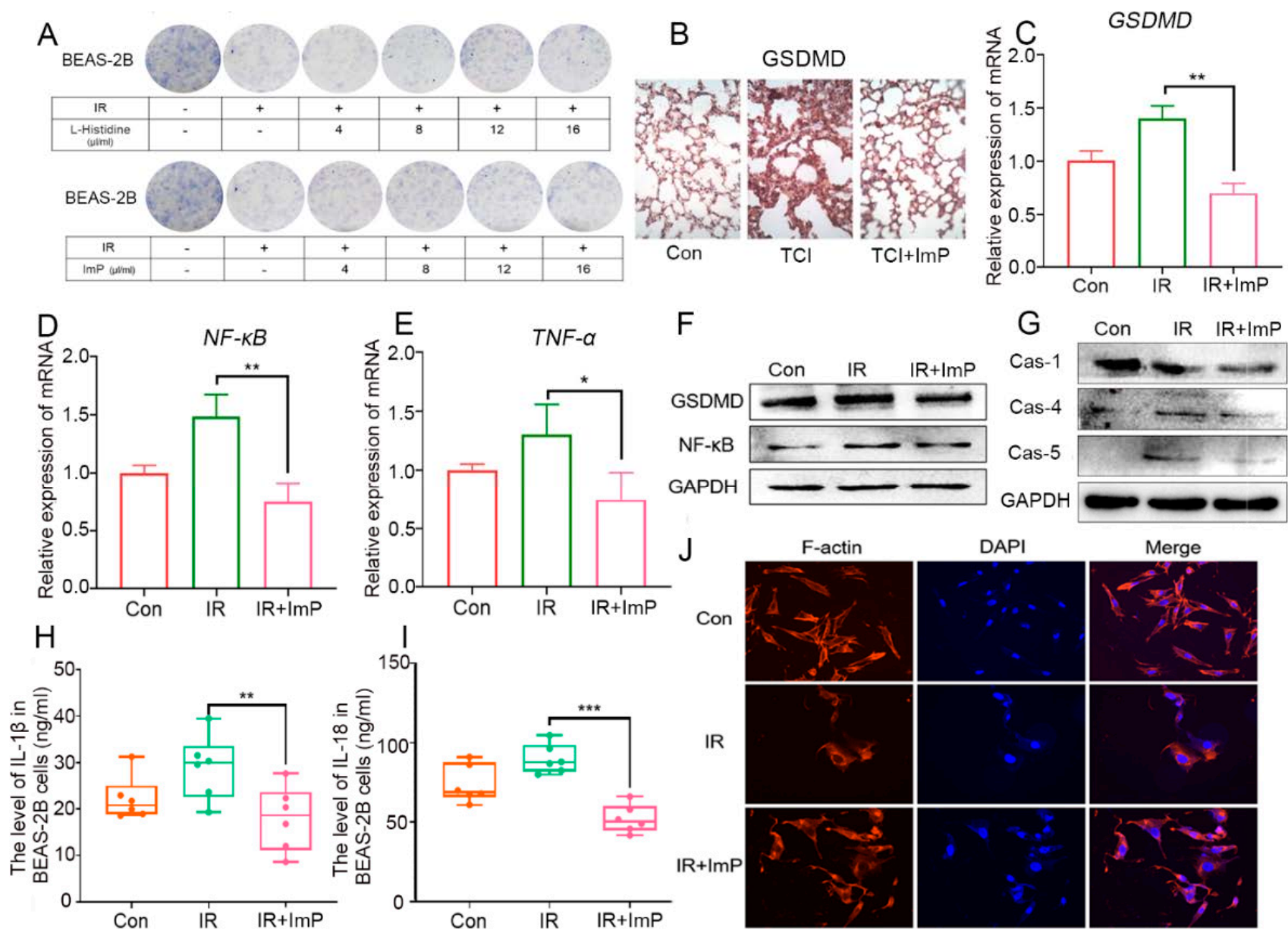

Figure 7. Imidazole propionate inhibits pyrolysis of irradiated lung cells. (A) The radiation sensitivity of BEAS-2B cells for L-Histidine and ImP in different densities were assessed through a clone formation experiment after radiation. (B) The GSDMD of irradiated lung tissues was analyzed by IHC. (C) The GSDMD of irradiated BEAS-2B cells was analyzed by qRT-PCR. (D,E) The relative expression of NF- $\mathrm{kB}$ and TNF- $\alpha$ mRNA in irradiated BEAS-2B cells were assessed by qRT-PCR $(n=6)$. (F) The GSDMD and NF-kB expression in irradiated BEAS-2B cells were examined by Western blotting. (G) The caspase-1, caspase-4, and caspase-5 expression in irradiated BEAS-2B cells were examined by Western blotting. (H,I) The level of IL-1 $\beta$ and IL-18 in irradiated BEAS-2B cells $(n=6)$. (J) Immunofluorescence showed the F-actin expression in irradiated BEAS-2B cells. (The data are presented as mean $\pm \mathrm{SD},{ }^{*} p<0.05,{ }^{* *} p<0.01$ and ${ }^{* * *} p<0.001$; Student's $t$-test). 


\section{Discussion}

Although high-energy ionizing radiation can kill cancer cells successfully, at the same time, it harms to the surrounding healthy tissues unavoidably and leads to various adverse side effects [21]. Radiotherapy has been widely used in thoracic malignancies, including breast cancer, lung cancer, esophageal cancer, thymoma, and Hodgkin's lymphoma, which are located close to the heart and lungs anatomically [22]. During radiotherapy for thorax cancers, the heart and lungs may be at risk of being exposed to the irradiation field, producing multiple dose-dependent complications [23]. Despite the significant advances in the delivery technology used for radiotherapy, up to $30 \%$ of patients receiving thoracic radiotherapy still suffer from radiation-induced lung injury (RILI) [24]. Give the cumulative dose to the heart in radiotherapy for lung cancer, breast cancer, and lymphoma [25], radiationinduced heart disease is also common and worthy of attention. In a large population-based study, patients with left breast cancer who received radiotherapy were at $25 \%$ more risk of experiencing a cardiac event [26]. Radiation-induced cardiopulmonary injuries escalate as major dose limitation obstacles and degrade the life quality of cancer survivors. Heretofore, safe and effective remedies for these complications are still lacking in clinical scenarios.

Recent efforts have identified the close relationship between the gut microbiome and the cardiopulmonary system. For instance, fecal microbiota transplantation (FMT) has been reported to protect against radiation pneumonia [27]. However, FMT represents limitations in clinical applications, including aesthetic concerns, costs of donor screening, and material preparation and administration. Thus, screening radioprotective agents from the gut microbiome to substitute for FMT and fight against radiation toxicity is a novel and promising therapeutic avenue. Recently, mounting evidence have proven that gut microbiota-derived metabolites play important roles in lung injury and rehabilitation. For example, acetate dampens the activation of NLRP3 inflammasomes in neonatal mice with bronchopulmonary dysplasia and protects lung injury [28]; the L-tyrosine pathway, a metabolite produced by enteric microbes, impacts the airway epithelium at the distal end to reduce allergic airway reactions [29]. Phycocyanin is a light-harvesting pigment protein isolated from cyanobacteria that regulates the radiation-induced disturbance of the lung and intestinal flora of mice and reduces radiation-induced lung inflammation and fibrosis [30]. In this study, gut microbiota-derived L-Histidine drew our attention because the relative level of L-Histidine in fecal pellets decreased after local chest irradiation but increased after FMT. L-Histidine is an essential amino acid. The 2005 report of the American Institute of Medicine on diet recommends the intake of $4 \mathrm{~g}$ of L-Histidine daily [31]. L-Histidine has a unique role in proton buffering, metal ion chelation, the removal of reactive oxygen and nitrogen substances, and in erythropoiesis and histaminergic systems. L-Histidine has been proven to treat rheumatoid arthritis and anemia in patients with chronic renal failure [32]. L-Histidine was employed as an important component of preparation for organ preservation and myocardial protection in cardiac surgery [33]. In addition, studies have reported that carnosine (beta-alanyl-1-histidine) represents radioprotective effects on wound healing in rats [34] and can reduce radiation-induced lung damage [35]. In the present study, we screened out a single L-Histidine from intestinal microorganismproduced metabolites and found that oral gavage of L-Histidine educated and tuned the gut bacteria taxonomic proportions of local chest-irradiated mice. Importantly, the replenishment of L-Histidine via the oral route not only resisted radiation-induced respiratory dysfunction but also attenuated radiation-induced cardiac toxicity depending on the gut microbiota, at least partly.

L-Histidine can be catabolized into two classic secondary metabolites, imidazole propionate and histamine. Therefore, it is interesting to unravel whether L-Histidine protects against irradiation directly or relies on the downstream metabolites. To answer the question, we performed a battery of experiments. First, we used ABX to clean gut microbes. The gut microbiota-deleted mice did not respond to L-Histidine treatment and exhibited similar radiation-induced cardiopulmonary injuries to the chest of the localirradiated controls. This suggests that destructing the metabolic function of the gut flora 
lull the radioprotective effects of L-Histidine. Secondly, we assessed the levels of ImP and histamine in PB and lung tissues from experimental mice with L-Histidine replenishment. The results show that only ImP was enriched in the target tissues. In addition, the oral gavage of $\operatorname{ImP}$ ameliorated radiation-induced cardiopulmonary toxicity, indicating that $\mathrm{ImP}$ might be the key secondary metabolites of L-Histidine to fight against radiation injuries. Finally, the experimental mice were treated with vancomycin or streptomycin, respectively. Results showed that the oral gavage of ImP cannot be enriched in PB and lung tissues in vancomycin-treated, Gram-positive bacteria-deleted mice, suggesting that gut commensal Gram-positive bacteria might play key roles in the absorption of ImP. Together, all of the evidence suggests that the gut microbiota might catabolize L-Histidine into ImP and assist in the entry of ImP into the circulatory system to protect against radiation-induced cardiopulmonary toxicity.

Acute pneumonia occurs within a few weeks after radiation and is characterized by the release of pro-inflammatory factors and the accumulation of immune cells in lung tissues. Research has reported that ionizing radiation precipitates pyroptosis in multiple tissues and organs (such as intestinal epithelium, liver, and muscle) [36]. Pyroptosis is programmed cell death, which is characterized as the formation of cell membrane pores, cytoplasmic swelling, membrane rupture, and the release of cytoplasmic contents (such as IL-1 $\beta$ ) into the extracellular environment, amplifying local or systemic inflammatory responses [37]. Gasdermin D (GSDMD) is a major protein family that is related to pyroptosis and is involved in many inflammatory diseases and cancers [38]. Cleaved GSDMD forms transmembrane pores to enable the release of IL-1 and drive cell lysis through pyroptosis $[39,40]$. Caspase- 1 also cleaves the inactive precursors in the IL- 1 family to generate mature cytokines such as IL-1 $\beta$ and IL-18 [41,42]. In the present study, irradiation exposure elevated the expression of GSDMD in vitro and in vivo. In BEAS-2B cells, the expression of caspase- 1 , caspase- 4 , and caspase- 5 were up-regulated after radiation stimuli, and the levels of IL- $1 \beta$ and IL-18 in culture medium were also heightened. In addition, the fluorescence intensity of the cytoskeleton protein F-actin was weakened and discontinuous after irradiation. All of these observations bolster the idea that irradiation nudged pyroptosis in lung cells after radiation challenge. Notably, ImP treatment inhibited the radiation-induced pyroptosis of lung cells. Given that NF-KB is an essential transcription factor for GSDMD [43,44]. ImP significantly blunted the increase of NF- $\mathrm{kB}$ after irradiation. It has been reported that the pre-treatment of glioma cells with a pyrrole-imidazole (Py-Im) polyamide prior to exposure to ionizing radiation resulted in a delay in the resolution of phosphorylated $\gamma-\mathrm{H} 2 \mathrm{AX}$ foci that are indicative of the delayed repair of double-stranded breaks [45]. However, ImP, the classic downstream metabolite of L-Histidine, activated different signaling pathways to perform radioprotective functions in radiation-induced lung injury. Thus, our findings indicate that ImP fight against radiation-induced cardiopulmonary injuries through inhibiting pyroptosis.

\section{Materials and Methods}

\subsection{Animals}

Six- to eight-week-old-male (around $20 \mathrm{~g}$ ) C57BL/6J mice were purchased from the Beijing Huafukang Bioscience Co., Inc. (Beijing, China). Mice were housed in the Specific Pathogen Free (SPF) level animal facility at the Institute of Radiation Medicine (IRM), the Chinese Academy of Medical Sciences (CAMS). All animal procedures were reviewed and approved by the Institutional Animal Care and Use Committee at CAMS.

\subsection{Cell Culture}

BEAS-2B cells were obtained from the American Type Culture Collection (ATCC) and were certified to be mycoplasma-free. The passage numbers of those cell lines during the experimental period were no more than eight. The cells were cultured with $10 \%$ fetal bovine serum (Gibco, Grand Island, NY, USA), $100 \mathrm{U} / \mathrm{mL}$ penicillin, and $100 \mathrm{mg} / \mathrm{mL}$ streptomycin and were grown at $5 \% \mathrm{CO}_{2}$ and $37^{\circ} \mathrm{C}$. 


\subsection{Irradiation Study}

A Gammacell-40 137Cs irradiator (Atomic Energy of Canada Limited, Chalk River, $\mathrm{ON}$, Canada) at a dose rate of 0.8 Gy per minute was used for all experiments. Mice treated with total chest irradiation (TCI) were exposed to 15 Gy $\gamma$-ray, and control mice were sham-irradiated. Mice were intragastrically administered L-Histidine (Aladdin, CAS: 71-00-1, Shanghai, China) and imidazole propionate (Aladdin, 165812, CAS: 1074-59-5, Shanghai, China) at a dose of around $200 \mu \mathrm{L}$ per mouse. Mice were sacrificed, and tissue samples were collected after the 21-day course of the experiment. BEAS-2B cells were exposed to $4 \mathrm{~Gy}$ (for colony formation assays) or $6 \mathrm{~Gy}$ (for other cell experiments).

\subsection{Fecal Microbiota Transplantation (FMT)}

For FMT administration, donor stool was freshly prepared on the day of transplant and within $4 \mathrm{~h}$ of transplantation. Donor stool was weighed and diluted with $2 \mathrm{~mL}$ of saline per $0.1 \mathrm{~g}$ of stool. In brief, the stool was steeped in saline for about $15 \mathrm{~min}$, shaken, and then centrifuged at $800 \times g \mathrm{rpm}$ for $3 \mathrm{~min}$. The supernatant was obtained for treatment. Mice in the FMT group were gavaged with the supernatant $200 \mu \mathrm{L}$ for 7 days before irradiation and then for 10 days after irradiation. TCI groups were given equal doses of placebo. The schematic diagram of FMT procedure is shown in the Supplementary Information (Figure S5).

\subsection{Antibiotic Cocktail (ABX) Administration}

$\mathrm{ABX}$ consisted of ciprofloxacin $(0.125 \mathrm{~g} / \mathrm{L})$, metronidazole $(0.1 \mathrm{~g} / \mathrm{L})$, vancomycin $(0.05 \mathrm{~g} / \mathrm{L})$, streptomycin $(100 \mathrm{U} / \mathrm{L})$, and penicillin $(100 \mathrm{U} / \mathrm{L})$. Mice were exposed to ABX in drinking water after TCI. The same water was used for the water-treated (TCI + LHistidine/ImP) group. Mice in the ABX group were housed with ABX fluid in their drinking water for 7 days before irradiation and then for 21 days after irradiation. The schematic diagram of the ABX procedure is shown in the Supplementary Information (Figure S6).

\subsection{Enzyme-Linked Immunosorbent Assay (ELISA)}

Frozen lung samples were ground up and reconstituted in PBS to a final concentration of $0.1 \mathrm{~g} / 300 \mu \mathrm{L}$, followed by centrifugation for $10 \mathrm{~min}$ at $8000 \times \mathrm{g}$ and $4{ }^{\circ} \mathrm{C}$. Serum was collected using ethylenediaminetetraacetic acid (EDTA) as an anticoagulant. Serum was centrifuged for $15 \mathrm{~min}$ at $1000 \times \mathrm{g}$ and $4{ }^{\circ} \mathrm{C}$. Protein level was measured from the clear supernatant using an ELISA kit (Solarbio, Beijing, China) according to the manufacturer's protocols. The supernatant was obtained to assess the level of ImP using the ELISA kit (F30264-A, mlBio, Shanghai, China) according to the manufacturer's protocols (Zcibio, Shanghai, China). Optical density was read at $450 \mathrm{~nm}$ (Rayto, Shenzhen, China). (TNF- $\alpha$, ml002095; TGF- $\beta 1$, ml057830; IL-1, ml037875; mlBio, Shanghai, China.) The L-Histidine (or propionate imidazole) level in the lung tissues and serum were assessed in L-Histidine (or propionate imidazole) replenishment mouse models (mice with normal gut microbiota) and ABX-treated mouse models (gut microbiota-deleted mice).

\subsection{Immunohistochemistry (IHC)}

First, the slides were baked at $65^{\circ} \mathrm{C}$, and then the xylene solution was dewaxed, and different gradients of alcohol were dehydrated. After the dewaxing was completed, $3 \%$ $\mathrm{H}_{2} \mathrm{O}_{2}$ was added to the slide specimens. The slide was put into a $0.01 \mathrm{M}$ citrate buffer $(\mathrm{pH}$ 6.0) pot and was heated at $95^{\circ} \mathrm{C}$ for antigen retrieval to be performed. After being blocked with normal goat serum, the prepared primary antibody should continue to be dropped and incubated overnight in a refrigerator at $4{ }^{\circ} \mathrm{C}$. On the second day, the biotin-labeled goat anti-rabbit secondary antibody working solution was incubated at room temperature for $10 \mathrm{~min}$; the HRP-labeled horseradish peroxidase-labeled working solution was incubated at $37^{\circ} \mathrm{C}$ for $10 \mathrm{~min}$; the slices were dripped with newly configured $\mathrm{DAB}$ chromogenic 
solution; hematoxylin was counter-stained for $2 \mathrm{~min}$; finally, the slides were dehydrated and mounted with neutral gum.

\subsection{Colony Formation Assays}

For colony formation analysis, $48 \mathrm{~h}$ after irradiation, 500 viable irradiated (transfected) cells were placed in 6-well plates and were maintained in complete medium for 2 weeks. Then, colonies were fixed with methanol and were stained with methylene blue.

\subsection{Bronchoalveolar Lavage Fluid (BALF)}

Mice were sacrificed, and one side of the bronchus was ligated, and the airway on the other side was lavaged three times with $800 \mu \mathrm{L}$ ice-cold PBS. A total of $80 \%$ of the input volume was recovered, which was defined as BALF. BALF was centrifuged at $500 \times g$ for $10 \min$ at $4{ }^{\circ} \mathrm{C}$.

\subsection{Respiratory Metabolism}

We used the Panlab Oxylet system (Panlab, OXYLET, Spain) to monitor the 24-h RQ $\left(\mathrm{O}_{2} / \mathrm{CO}_{2}\right)$, oxygen intake $\mathrm{VO}_{2}\left(\mathrm{~mL} / \mathrm{min} / \mathrm{kg}^{\wedge} 0.75\right)$, and carbon dioxide emissions $\left(\mathrm{VCO}_{2}\right.$ $\left(\mathrm{mL} / \mathrm{min} / \mathrm{kg}^{\wedge} 0.75\right)$ of the mice in each group. Before monitoring, the system needed to be calibrated: low $\mathrm{O}_{2}(20 \%)$, high $\mathrm{O}_{2}(50 \%)$, low $\mathrm{CO}_{2}(0 \%)$, high $\mathrm{CO}_{2}(1.5 \%)$. Then, each mouse was weighed, and the average value was calculated. The mice were then placed in a metabolic cage. At this stage, the software should be opened in order to continuously monitor mice for $24 \mathrm{~h}$, and the software should be used to calculate the relevant data.

$\mathrm{VO}_{2}$ and $\mathrm{VCO}_{2}$ weighted complete equations:

$$
\begin{aligned}
& V O_{2}=\frac{\left(F \times \frac{\left[\mathrm{O}_{2}\right]_{e}}{100}\right)-\frac{\frac{\left[\mathrm{O}_{2}\right]_{s}}{100} \times F \times\left(1-\frac{\left[\mathrm{O}_{2}\right]_{e}}{100}-\frac{\left[\mathrm{CO}_{2}\right]_{e}}{100}\right)}{\left(1-\frac{\left[\mathrm{O}_{2}\right]_{s}}{100}-\frac{\left[\mathrm{CO}_{2}\right]_{s}}{100}\right)}}{W^{k}} \\
& V \mathrm{CO}_{2}=\frac{\frac{F \times\left(1-\frac{\left[\mathrm{O}_{2}\right]_{e}}{100}-\frac{\left[\mathrm{CO}_{2}\right]_{e}}{100}\right)}{\left(1-\frac{\left[\mathrm{O}_{2}\right]_{s}}{100}-\frac{\left[\mathrm{CO}_{2}\right]_{s}}{100}\right)} \times \frac{\left[\mathrm{CO}_{2}\right]_{s}}{100}-\frac{\left[\mathrm{CO}_{2}\right]_{e}}{100} \times F}{W^{k}} \\
& R Q \text { weighted equations : } R Q=\frac{V C O_{2}}{V O_{2}}
\end{aligned}
$$

\subsection{CODA Noninvasive Blood Pressure System}

The blood pressure of the mice was measured by means of a modern high-precision and noninvasive method using the CODATM Standard system (Kent Scientific Corporation, Torrington, CT, USA). This method uses a specialized volume pressure recording (VPR) sensor that are placed over the animal's tail to measure blood volume changes. The mice do need to be restrained and artificially heated in specific holders in order to maintain normal BP.

\subsection{Statistical Analysis}

Each experiment was repeated at least three times. The normal distribution of the data was assessed using the Kolmogorov-Smirnov test. The data are presented as the means \pm SD with respect to the number of samples $(n)$ in each group. Significance was assessed by comparing the mean values using Student's $t$-test and the Wilcoxon rank sum test for independent groups as follows: ${ }^{*} p<0.05 ;{ }^{* *} p<0.01$; ${ }^{* * *} p<0.001$.

\section{Conclusions}

Together, our study provides novel insights into the gut microbiota-derived metabolites and underpins that gut flora-produced L-Histidine/ImP can protect against radiation- 
induced cardiopulmonary toxicity. Mechanistic investigation showed that the radioprotective function of L-Histidine or ImP is dependent of gut microbiota. Clinically, L-Histidine or ImP might be employed as a potential and promising radioprotective agent to fight against radiotherapy intertwined cardiopulmonary injury.

Supplementary Materials: The following are available online at https:/ / www.mdpi.com/article/10 $.3390 /$ ijms222111436/s1.

Author Contributions: The authors' responsibilities were as follows: Z.C., H.X. and M.C. designed and performed the experiments, analyzed the data, and wrote the paper. B.W., J.D., Y.L., S.Z. and X.Z. performed the experiments. S.F. oversaw the entire project. All authors have read and agreed to the published version of the manuscript.

Funding: This research was funded by the Science Foundation for Distinguished Young Scholars of Tianjin (20JCJQJC00100) and the Natural Science Foundation of China under Grant (number 81872555, 81803062, 82003399, 81730086 and 32100087).

Institutional Review Board Statement: The study was conducted according to the guidelines of the Declaration of Helsinki and was approved by the Chinese Academy of Medical Sciences (CAMS) (protocol code 2020-166 and 06 March 2020).

Informed Consent Statement: Not applicable.

Data Availability Statement: Not applicable.

Acknowledgments: The authors would like to thank Saijun Fan and Ming Cui for their valuable input. We are very grateful for the excellent technical assistance from Bin Wang, Jiali Dong, Yuan Li, Shuqin Zhang, Huiwen Xiao, and Xiaozhou Zeng.

Conflicts of Interest: The authors declare no conflict of interest.

\section{References}

1. Jairam, V.; Lee, V.; Park, H.S.; Thomas, C.J.; Melnick, E.R.; Gross, C.P.; Presley, C.J.; Adelson, K.B.; Yu, J.B. Treatment-Related Complications of Systemic Therapy and Radiotherapy. JAMA Oncol. 2019, 5, 1028-1035. [CrossRef] [PubMed]

2. Citrin, D.E. Recent Developments in Radiotherapy. N. Engl. J. Med. 2017, 377, 1065-1075. [CrossRef] [PubMed]

3. Jacobson, G.; Lawrence, Y.R.; Appel, S.; Weiss, I.; Ben, A.M.; Akiva, B.M.; Peled, N.; Goldstein, J.D.; Weizman, N.; Galper, S.; et al. Benefits of Continuous Positive Airway Pressure (CPAP) During Radiation Therapy: A Prospective Trial. Int. J. Radiat. Oncol. Biol. Phys. 2021, 110, 1466-1472. [CrossRef]

4. Giridhar, P.; Mallick, S.; Rath, G.K.; Julka, P.K. Radiation induced lung injury: Prediction, assessment and management. Asian Pac. J. Cancer Prev. 2015, 16, 2613-2617. [CrossRef]

5. Yap, M.L.; Zubizarreta, E.; Bray, F.; Ferlay, J.; Barton, M. Global Access to Radiotherapy Services: Have We Made Progress During the Past Decade? J. Glob. Oncol. 2016, 2, 207-215. [CrossRef] [PubMed]

6. Huang, E.X.; Hope, A.J.; Lindsay, P.E.; Trovo, M.; El, N.I.; Deasy, J.O.; Bradley, J.D. Heart irradiation as a risk factor for radiation pneumonitis. ACTA Oncol. 2011, 50, 51-60. [CrossRef]

7. Myers, C.J.; Lu, B. Decreased Survival After Combining Thoracic Irradiation and an Anti-PD-1 Antibody Correlated With Increased T-cell Infiltration Into Cardiac and Lung Tissues. Int. J. Radiat. Oncol. Biol. Phys. 2017, 99, 1129-1136. [CrossRef]

8. Speirs, C.K.; DeWees, T.A.; Rehman, S.; Molotievschi, A.; Velez, M.A.; Mullen, D.; Fergus, S.; Trovo, M.; Bradley, J.D.; Robinson, C.G. Heart Dose Is an Independent Dosimetric Predictor of Overall Survival in Locally Advanced Non-Small Cell Lung Cancer. J. Thorac. Oncol. 2017, 12, 293-301. [CrossRef]

9. Wang, K.; Eblan, M.J.; Deal, A.M.; Lipner, M.; Zagar, T.M.; Wang, Y.; Mavroidis, P.; Lee, C.B.; Jensen, B.C.; Rosenman, J.G.; et al. Cardiac Toxicity After Radiotherapy for Stage III Non-Small-Cell Lung Cancer: Pooled Analysis of Dose-Escalation Trials Delivering 70 to 90 Gy. J. Clin. Oncol. 2017, 35, 1387-1394. [CrossRef]

10. Ghobadi, G.; van der Veen, S.; Bartelds, B.; de Boer, R.A.; Dickinson, M.G.; de Jong, J.R.; Faber, H.; Niemantsverdriet, M.; Brandenburg, S.; Berger, R.M.; et al. Physiological interaction of heart and lung in thoracic irradiation. Int. J. Radiat. Oncol. Biol. Phys. 2012, 84, e639-e646. [CrossRef]

11. van Nimwegen, F.A.; Ntentas, G.; Darby, S.C.; Schaapveld, M.; Hauptmann, M.; Lugtenburg, P.J.; Janus, C.; Daniels, L.; van Leeuwen, F.E.; Cutter, D.J.; et al. Risk of heart failure in survivors of Hodgkin lymphoma: Effects of cardiac exposure to radiation and anthracyclines. Blood 2017, 129, 2257-2265. [CrossRef] [PubMed]

12. Wang, S.; Xu, M.; Wang, W.; Cao, X.; Piao, M.; Khan, S.; Yan, F.; Cao, H.; Wang, B. Systematic Review: Adverse Events of Fecal Microbiota Transplantation. PLoS ONE 2016, 11, e0161174. [CrossRef] [PubMed]

13. Willis, K.A.; Stewart, J.D.; Ambalavanan, N. Recent Advances in Understanding the Ecology of the Lung Microbiota and Deciphering the Gut-Lung Axis. Am. J. Physiol. Lung. Cell Mol. Physiol. 2020, 319, L710-L716. [CrossRef] [PubMed] 
14. Pinkerton, J.W.; Kim, R.Y.; Robertson, A.; Hirota, J.A.; Wood, L.G.; Knight, D.A.; Cooper, M.A.; O’Neill, L.; Horvat, J.C.; Hansbro, P.M. Inflammasomes in the lung. Mol. Immunol. 2017, 86, 44-55. [CrossRef]

15. Zeng, C.; Tan, H. Gut Microbiota and Heart, Vascular Injury. Adv. Exp. Med. Biol. 2020, 1238, 107-141.

16. Enaud, R.; Prevel, R.; Ciarlo, E.; Beaufils, F.; Wieers, G.; Guery, B.; Delhaes, L. The Gut-Lung Axis in Health and Respiratory Diseases: A Place for Inter-Organ and Inter-Kingdom Crosstalks. Front. Cell. Infect. Microbiol. 2020, 10, 9. [CrossRef] [PubMed]

17. Yamashita, T.; Yoshida, N.; Emoto, T.; Saito, Y.; Hirata, K.I. Two Gut Microbiota-Derived Toxins Are Closely Associated with Cardiovascular Diseases: A Review. Toxins 2021, 13, 297. [CrossRef]

18. Liu, G.; Li, J.; Li, Y.; Hu, Y.; Franke, A.A.; Liang, L.; Hu, F.B.; Chan, A.T.; Mukamal, K.J.; Rimm, E.B.; et al. Gut microbiota-derived metabolites and risk of coronary artery disease: A prospective study among US men and women. Am. J. Clin. Nutr. 2021, 114, 238-247. [CrossRef]

19. Koh, A.; Molinaro, A.; Stahlman, M.; Khan, M.T.; Schmidt, C.; Manneras-Holm, L.; Wu, H.; Carreras, A.; Jeong, H.; Olofsson, L.E.; et al. Microbially Produced Imidazole Propionate Impairs Insulin Signaling through mTORC1. Cell 2018, 175, 947-961.e17. [CrossRef]

20. Jiang, R.; Xu, J.; Zhang, Y.; Zhu, X.; Liu, J.; Tan, Y. Ligustrazine Alleviate Acute Lung Injury Through Suppressing Pyroptosis and Apoptosis of Alveolar Macrophages. Front. Pharmacol. 2021, 12, 680512. [CrossRef]

21. Menezes, K.M.; Wang, H.; Hada, M.; Saganti, P.B. Radiation Matters of the Heart: A Mini Review. Front. Cardiovasc. Med. 2018, 5, 83. [CrossRef]

22. Stewart, F.A.; Seemann, I.; Hoving, S.; Russell, N.S. Understanding radiation-induced cardiovascular damage and strategies for intervention. Clin. Oncol. 2013, 25, 617-624. [CrossRef]

23. Taylor, C.; Correa, C.; Duane, F.K.; Aznar, M.C.; Anderson, S.J.; Bergh, J.; Dodwell, D.; Ewertz, M.; Gray, R.; Jagsi, R.; et al. Estimating the Risks of Breast Cancer Radiotherapy: Evidence From Modern Radiation Doses to the Lungs and Heart and From Previous Randomized Trials. J. Clin. Oncol. 2017, 35, 1641-1649. [CrossRef]

24. Zanoni, M.; Cortesi, M.; Zamagni, A.; Tesei, A. The Role of Mesenchymal Stem Cells in Radiation-Induced Lung Fibrosis. Int. J. Mol. Sci. 2019, 20, 3876. [CrossRef]

25. Banfill, K.; Giuliani, M.; Aznar, M.; Franks, K.; McWilliam, A.; Schmitt, M.; Sun, F.; Vozenin, M.C.; Faivre, F.C. Cardiac Toxicity of Thoracic Radiotherapy: Existing Evidence and Future Directions. J. Thorac. Oncol. 2021, 16, 216-227. [CrossRef] [PubMed]

26. De Ruysscher, D.; Niedermann, G.; Burnet, N.G.; Siva, S.; Lee, A.; Hegi-Johnson, F. Radiotherapy toxicity. Nat. Rev. Dis. Primers 2019, 5, 13. [CrossRef]

27. Nie, X.; Li, L.; Yi, M.; Qin, W.; Zhao, W.; Li, F.; Wu, B.; Yuan, X. The Intestinal Microbiota Plays as a Protective Regulator Against Radiation Pneumonitis. Radiat. Res. 2020, 194, 52-60. [CrossRef]

28. Zhang, Q.; Ran, X.; He, Y.; Ai, Q.; Shi, Y. Acetate Downregulates the Activation of NLRP3 Inflammasomes and Attenuates Lung Injury in Neonatal Mice With Bronchopulmonary Dysplasia. Front. Pediatr. 2020, 8, 595157. [CrossRef]

29. Wypych, T.P.; Pattaroni, C.; Perdijk, O.; Yap, C.; Trompette, A.; Anderson, D.; Creek, D.J.; Harris, N.L.; Marsland, B.J. Microbial metabolism of L-tyrosine protects against allergic airway inflammation. Nat. Immunol. 2021, 22, 279-286. [CrossRef] [PubMed]

30. Li, W.; Lu, L.; Liu, B.; Qin, S. Effects of phycocyanin on pulmonary and gut microbiota in a radiation-induced pulmonary fibrosis model. Biomed. Pharmacother. 2020, 132, 110826. [CrossRef] [PubMed]

31. Gibbs, N.K. 1-Histidine Supplementation in Adults and Young Children with Atopic Dermatitis (Eczema). J. Nutr. 2020, 150 (Suppl. S1), 2576S-2579S. [CrossRef] [PubMed]

32. Holecek, M. Histidine in Health and Disease: Metabolism, Physiological Importance, and Use as a Supplement. Nutrients 2020, 12, 848. [CrossRef] [PubMed]

33. Rao, F. Systematic review of preservation solutions for allografts for liver transplantation based on a network meta-analysis. Int J. Surg. 2018, 54, 1-6. [CrossRef] [PubMed]

34. Tanaka, R.A.; Ramos, F.M.; Almeida, S.M.; Vizioli, M.R.; Boscolo, F.N. Evaluation of radioprotective effect of carnosine (betaalanyl-1-histidine) on the wound healing in rats. J. Appl. Oral Sci. 2005, 13, 253-258. [CrossRef] [PubMed]

35. Guney, Y. Carnosine may reduce lung injury caused by radiation therapy. Med. Hypotheses 2006, 66, 957-959. [CrossRef] [PubMed]

36. Gao, J.; Peng, S.; Shan, X.; Deng, G.; Shen, L.; Sun, J.; Jiang, C.; Yang, X.; Chang, Z.; Sun, X.; et al. Inhibition of AIM2 inflammasomemediated pyroptosis by Andrographolide contributes to amelioration of radiation-induced lung inflammation and fibrosis. Cell Death Dis. 2019, 10, 957. [CrossRef]

37. Fink, S.L.; Bergsbaken, T.; Cookson, B.T. Anthrax lethal toxin and Salmonella elicit the common cell death pathway of caspase-1dependent pyroptosis via distinct mechanisms. Proc. Natl. Acad. Sci. USA 2008, 105, 4312-4317. [CrossRef] [PubMed]

38. Wang, K.; Sun, Q.; Zhong, X.; Zeng, M.; Zeng, H.; Shi, X.; Li, Z.; Wang, Y.; Zhao, Q.; Shao, F.; et al. Structural Mechanism for GSDMD Targeting by Autoprocessed Caspases in Pyroptosis. Cell 2020, 180, 941-955.e20. [CrossRef]

39. Xia, S.; Zhang, Z.; Magupalli, V.G.; Pablo, J.L.; Dong, Y.; Vora, S.M.; Wang, L.; Fu, T.M.; Jacobson, M.P.; Greka, A.; et al. Gasdermin D pore structure reveals preferential release of mature interleukin-1. Nature 2021, 593, 607-611. [CrossRef]

40. Zhou, B.; Abbott, D.W. Gasdermin E permits interleukin-1 beta release in distinct sublytic and pyroptotic phases. Cell Rep. 2021, 35, 108998. [CrossRef]

41. Karmakar, M.; Minns, M.; Greenberg, E.N.; Diaz-Aponte, J.; Pestonjamasp, K.; Johnson, J.L.; Rathkey, J.K.; Abbott, D.W.; Wang, K.; Shao, F.; et al. N-GSDMD trafficking to neutrophil organelles facilitates IL-1beta release independently of plasma membrane pores and pyroptosis. Nat. Commun. 2020, 11, 2212. [CrossRef] [PubMed] 
42. Maelfait, J.; Vercammen, E.; Janssens, S.; Schotte, P.; Haegman, M.; Magez, S.; Beyaert, R. Stimulation of Toll-like receptor 3 and 4 induces interleukin-1beta maturation by caspase-8. J. Exp. Med. 2008, 205, 1967-1973. [CrossRef] [PubMed]

43. Liu, Z.; Gan, L.; Xu, Y.; Luo, D.; Ren, Q.; Wu, S.; Sun, C. Melatonin alleviates inflammasome-induced pyroptosis through inhibiting NF-kappaB/GSDMD signal in mice adipose tissue. J. Pineal. Res. 2017, 63, 402-408. [CrossRef] [PubMed]

44. Gao, Y.; Xiao, X.; Zhang, C.; Yu, W.; Guo, W.; Zhang, Z.; Li, Z.; Feng, X.; Hao, J.; Zhang, K.; et al. Melatonin synergizes the chemotherapeutic effect of 5-fluorouracil in colon cancer by suppressing PI3K/AKT and NF-kappaB/iNOS signaling pathways. J. Pineal Res. 2017, 62, e12380. [CrossRef] [PubMed]

45. Diaz-Perez, S.; Kane, N.; Kurmis, A.A.; Yang, F.; Kummer, N.T.; Dervan, P.B.; Nickols, N.G. Interference with DNA repair after ionizing radiation by a pyrrole-imidazole polyamide. PLoS ONE 2018, 13, e196803. [CrossRef] 